\title{
An Experimental Evaluation of e-Commerce in Supply Chain Management among Indian Online Pharmacy Companies
}

\author{
Vipin Jain, Satyendra Arya, Rajeev Gupta
}

\begin{abstract}
Supply Chain Management is an external interface of logistics systems of the organizations with its clients, stakeholders and all other outsourcing parties with the aim to provide best services to all the customers. In India, the supply chain system plays a very important role in delivering the products to the customers. Due to the digitalization, most of the people purchase the products online, so role of e-commerce in supply chain management is going to be very crucial. This research paper shows about the online pharmacy system in India. The ides of this research paper is to present the state-of-the-art e-commerce logistics system of pharmacy in India. In this research paper, the researchers approach typical e-commerce companies which are deal in online pharmacy in India. The practical and social implication of this research paper is that awareness about online pharmacy among Indian citizens, so that they can purchase their medicines from at home and this will save the time and cost.
\end{abstract}

Keywords : E-Commerce, Logistics System of Pharmacy, Online Pharmacy and Supply Chain Management.

\section{INTRODUCTION}

The supply chain management is an administration of all the customary business functions deliberately between at least three firms legitimately connected by at least one of the upstream and downstream progressions of items, administrations, funds and data from a source to a client over any part of the framework. A Supply Chain as the system of associations that is included, through upstream and downstream linkages, in the various procedures and exercises that produce an incentive as items and administrations in the hands of extreme customers (Christopher, 1992).

Features of Supply Chain Management

The following are the prevalent features of Supply Chain Management:

$>$ Superior Customer Value

Single Entity

$>$ Inventory Perspective

Revised Manuscript Received on October 15, 2019.

* Correspondence Author

Prof. (Dr.) Vipin Jain, Principal, TMIMT, Teerthanker Mahaveer University, Moradabad-244001, Uttar Pradesh, India. Email: vipin555@rediffmail.com

Dr. Satyendra Arya, Associate Professor, Department of Management Studies, TMIMT, Teerthanker Mahaveer University, Moradabad-244001, Uttar Pradesh, India. Email: satyendra_arya17@rediffmail.com, satyendra.arya@gmail.com

Dr. Rajeev Gupta, Associate Professor, Department of Management Studies, TMIMT, Teerthanker Mahaveer University, Moradabad-244001, Uttar Pradesh, India.Email: prof.rajeevgupta@gmail.com
$>$ Strategic Orientation

$>$ Supply Chain Relationships

$>$ Flexible Approach

Supply Chain Management and Information Technology Following are some of the reasons behind an effective interface and linkage between supply chain management and information technology:

* Information Technology facilitates high degree of inter-functions integration and coordination within the firm.

* Information Technology enabled firms bring about inter-firm integration and coordination.

* IT enhances market responsiveness capabilities of firms by making supply chain more flexible to serve demanding markets in best ways.

* Information Technologies and systems such as Enterprise Resource Planning (ERP), Bar Coding, RFID Systems, etc., are important tools to improve the flow of information between firms resulting into optimization of resources across supply chain network.

* Real-time availability of information through the use of information technology reduces confusion ambiguity, uncertainty and risks across supply chain resulting into better understanding, trust and relationships.

IT Infrastructure for Supply Chain Management

A large portion of the corporate ventures are, significantly, putting resources into the advancement of a suitable IT Infrastructure for supply chain management as far as PC equipment, programming and availability by methods for Electronic Data Interchange (EDI), Bar Code System (BCS), Enterprise Resource Planning (ERP) and Internet as shown in figure 1 :

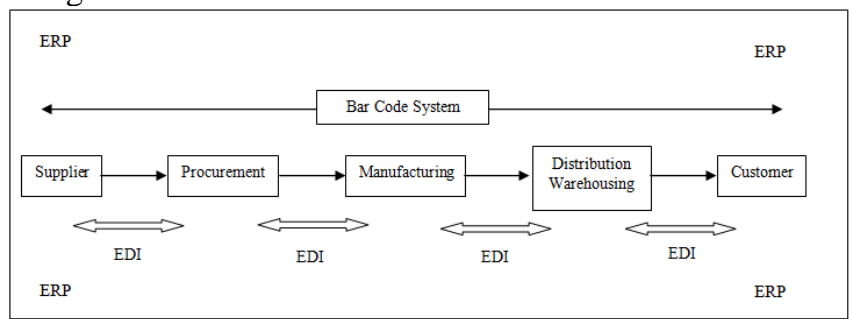

Figure 1 IT Infrastructure for Supply Chain Management

(Source: Agarwal, 2000) 


\section{An Experimental Evaluation of e-Commerce in Supply Chain Management among Indian Online Pharmacy Companies}

\section{E-Commerce}

Any development and improvement of Information Technology could on a very basic level change the economy. Any quest for finding compelling techniques for business undertakings has come about to another insurgency in business. It is named electronic commerce. $\mathrm{E}$ - commerce and electronic business are regular terms which contrasts from one another. These terms are in certainty equivalent to business exchanges, accommodation of administrations to clients and business obligations through advanced techniques. Firstly, it is important to clarify various terms in this field including IT, e-commerce and electronic business (Obrein, 2001).

E-commerce is impacted in supply chain financial effectiveness in following ways:

- Reducing the distribution and transactions costs.

- Increasing the speed of product development.

- Providing more information for buyers and sellers.

- Increasing the options of customer and their access to suppliers.

- Reducing the time intervals.

\section{Online Pharmacy}

An Online Pharmacy is a drug store that works over the internet and sends the requests to the clients through the messenger with the assistance of transportation organizations. This kind of drug stores may include:

$>$ Drug Store Administrator - Corporate prescription drug planner.

$>$ Genuine web based drug store present in that country where the person places the order.

$>$ Genuine web based drug store present in the other country that the persons places the order and in these drug stores, the license is provided by the home country and they have to follow all the rules and regulations of home country only. They are not bounded to follow the rules and regulation of that country from where the order is placed.

Ordinary stationary drug stores as a rule have controlled drug distribution systems from the producer. Approval and great circulation practices are pursued. Home conveyance of pharmaceuticals can be an alluring comfort. The shipment of medications through the courier is some of the time a worry for temperature touchy pharmaceuticals. Uncontrolled transporting conditions can incorporate high and low temperatures outside of the recorded stockpiling conditions for a drug.

\section{Risks and Concerns}

There are following risks and concerns regarding online pharmacy:

* Sometime drug stores send expired, non branded and outdated medicines.

* Often web based drug stores may not be located in the country where they claimed.

* In some of the cases drugs can be order by children without any consultation of professionals.

* There are many others concerns like: improper packaging, secrecy, etc.

\section{Research Objectives}

$>$ To study the role of e-commerce in Supply Chain Management among Indian Online Pharmacy Companies.

To study the customer satisfaction level from online pharmacy system.

\section{REVIEW OF LITERATURE}

Sahet. al. (2018) depicts in the research paper that, online drug stores giving a simple chance to buy enormous assortment of meds. These offer different preferences like lower costs, simple openness, doorstep conveyance and so forth. Online drug stores additionally convey with them weaknesses like absence of collaboration with doctor, administering of medications without solutions, selling of inadequate meds and so on. There is absence of learn about customer's mindfulness with respect to online drug store in India. Thus study was intended to survey buyer's mindfulness and conduct towards the utilization of online drug store benefits in the Delhi, India. Cross sectional, poll based investigation was directed to survey purchaser's mindfulness and conduct towards the utilization of online drug store administrations. In this examination albeit $85.8 \%$ of respondents knew about online drug store however just $6 \%$ of them acquired prescription through it. Vulnerability about convenient conveyance of prescriptions and supply of fake drugs were the real anxieties in regards to online drug stores among $85 \%$ and $75 \%$ of members separately. Variables preferences apportioning drugs without necessity of any medicine (91\%) and illicit site $(57 \%)$ were set apart as a normal for dubious online drug stores. Highlights like doorstep conveyance and update administrations were guaranteed as alluring highlights of online drug stores by $68 \%$ and $60.8 \%$ of members individually. Acquiring drugs from online drug stores was not a typical practice among the respondents. Shoppers should be instructed about the dangers and advantages related with purchasing drugs on the web. Instructive measures ought to be combined with satisfactory checking of online drug stores from administrative specialists.

Uttarwar and Riat (2018) described the concept of Lean Supply Chain and they depicted that this concept is picking up ubiquity as of late in Indian Industry. They featured that with the headway accomplished in Communication and Information Technology, associations presently have an incredible chance to decrease their working expenses by better coordination and proficient administration. They centered that tomorrow's store network is unquestionably going to be more worldwide and adaptable than any other time in recent memory. They portrayed that Indian associations need to change old attitude quick and be versatile the same number of the prior practices, for example, vertical incorporation, exchanging providers, and so forth are viewed as obsolete in the new economy. They featured that very soon; saw effect of assembling on condition will bring Green Supply Chain in core interest. Finally, they portrayed that cutting edge model of Supply Chain considering rising key patterns is going to profit Indian industry. 
Hertiget.al. (2017) depicted that there are an expected 32,500 online drug stores overall offering doctor prescribed meds to patients, of which $96 \%$ are working illicitly. Choices to buy from online drug stores might be affected by view of hazard. Flow research recommends that particular financial attributes and ebb and flow wellbeing status may incline people to tolerating or dismissing hazard. In this manner, it is essential to decide these potential indicators that energize utilization of online drug stores in spite of apparent risks. A institutionalized, 49 inquiry study by means of telephone was led by an agreement study research firm to gather information from 500 Indiana purchasers in regards to online drug store use, impression of hazard with online drug store use, and important statistic data. 33\% of those overviewed had obtained from an online drug store for themselves or for somebody under their consideration. Females and guys beyond 55 years old were destined to have obtained from an online drug store and those with the least family unit pay were well on the way to acknowledge apparent high hazard related with online drug store use. At last, of the individuals who acquired from an online drug store, over half got a referral from a doctor, nurture, as well as drug specialist. There are recognized relationship between statistic attributes or wellbeing status and online drug store chance discernment and hazard acknowledgment. Further research ought to be investigated to decide the effect of these qualities on hazard observation.

Xiao and Zhang (2017) depicted that the meaning of online business isn't only just exchanging and shopping on the web; it additionally implies business effectiveness at different operational levels. They depicted that the significance of Supply Chain Management is organizing, booking and controlling the acquisition, creation, inventories and conveyances of items and administrations to the clients. They upheld that Supply Chain Management is the foundation of web based business and its effectiveness implies the correct item at the opportune spot and at the perfect time; can decrease expenses and improve money usage. They clarified that, in the last 2 to 3 years, different organizations, in created and creating nations, have actualized their web stage for Supply Chain Efficiency and the enormous number of them will follow in the coming couple of years. At last, they reviewed that how Supply Chain Management can bring some benefits to the various corporations.

Ying et al. (2017) focused their study on the best in class web based business co-ordinations in the Supply Chain Management by researching overall executions and comparing models together with supporting systems. The methodology of their examination was normal web based business organizations from North America, Europe and some piece of Asia. They depicted that the future advancements like Internet of Things (IoT), Big information investigation and Cloud Computing would be potentially embraced to upgrade the web based business co-ordinations as far as framework level, operational level and basic leadership level that might be continuous and shrewd in the following 10 years. The down to earth ramifications of their examination is that invested individuals like online business and co-ordinations organizations can get some direction when they are pondering the business and the social ramifications of their investigation is that web based business is blasting with the advancement of new plans of action and will be constantly supported sooner rather than later. With enormous numbers of ventures, doing online business, co-ordinations have been to a great extent impacted.

Alameluet. al. (2016) described that to consider the medicine of medications through online retail is a chance or not for the end customers in an Indian setting. This paper portrayed the fundamental issues and moves identified with online pharmacy retail in the Indian setting through case strategy. India is among the main six worldwide pharmaceutical makers on the planet. The Indian antibodies are traded to 150 nations. India produces $40-70 \%$ of the World Health Organization (WHO) interest for Diphtheria-Pertussis-Tetanus and Bacille Calmette-Guérin antibody and $90 \%$ of measles immunization. Supported by the astonishing achievement accomplished by buyer durables industry in the online space, pharmacy is the following huge part in India to target purchaser on the web. The development in the business has made an extraordinary open door for the online model for this business. India has now observed pharmacy players taking the online business course with an aim to offer an answer for various issues tormenting the retail drug store industry. In spite of the fact that online medications resemble a promising pattern today, the business is tested by administrative issues.

Snyder and Rell (2013) described that current advancements have upset the way where retailers work. They portrayed that the beginning times of the website period enabled organizations to try different things with various plans of action. They clarified that on-line retailers concentrated uniquely at front-end frameworks and they neglected the significance of back-end activities, for example, Supply Chain Management. Their study explained that retailers have only two options for distributing their products and that traditional methods and drop shipping method. At last they explained that retailers now have another option i.e. e-commerce method.

Yang (2012) described about the basic principles, structure models and its advantages of Supply Chain Management under e-commerce environment. He also obtained and analyzed some problems, including light sense, weak core competitive forces, and lack of cooperation and low level of information in the application of Supply Chain Management. Nikakhtar and Jianzheng (2012) depicted that one of the extraordinary attributes of ongoing decades is concentrating supply chains on upper hand by a few associations. They depicted that then again, ongoing advances in Information Technologies (IT) are different components of changing business conditions. They supported that so as to locate a superior upper hand and make due in the market with every day expanding changes; all associations need a powerful system dependent on collaboration in inventory network the board. They depicted the internet business process also to portray store network and every one of its necessities and prerequisites in the present aggressive world. Moreover, their examination calls attention to the nature and favorable circumstances of rivalry and its need for monetary development in an economy. They likewise clarified that it is so conceivable to discover upper hand by the utilization of electronic inventory network as an essential and central factor in 


\section{An Experimental Evaluation of e-Commerce in Supply Chain Management among Indian Online Pharmacy}

Companies

fixed and support of subsequent stage and improve circumstance than different rivals in market and industry. They centered their exploration is the necessary regard for client and client inclination such that clients become the focal point of center and consideration of developers and chiefs. At long last there are various propositions for improvement of capacities in the field of upper hand through electronic inventory network also.

\section{Indian Consumers}

Online pharmacies in India have altogether expanded because of developing E- business and minimal guideline. No administrative authority over medication notices on TV or the Internet. Technology can help in gathering the healthcare services goal of India. Indian government wants to spend Rs Five Hundred Crore on literacy of computers.

\section{1) Legal Status in India}

There is no particular law to manage web based drug stores in India however various laws are present to oversee web based drug stores. For the clearance of Schedule H \& X the laws which are present are The Drugs and Cosmetics Act, 1940, and the Drugs and Cosmetics Rules, 1945. In January 2015, the Pharmacy Council of India pronounced the Pharmacy Practice Regulation about the internet based solution and Bar Coding for the selling of the medicines. On the ground of present norms, it creates the idea that a digital copy of prescription will be perfectly considered as a justifiable solution.. Be that as it may, regardless of whether such digitalized prescriptions can be utilized to purchase prescription from web based drug stores has been addressed.

\section{Online Pharmacies Laws in India}

There is no law to regulate web based drug stores in India. It is mainly regulated by provisions of IT Act 2000. But these provision are not sufficient to regulates this industry, due to which this sector is expanding in many folds.

\section{Recent Developments}

AIIMS (All India Institute of Medical Sciences) soon launching new services to book bed through web portal. Stocks of medicines will be online through which single stock of medicine can be utilized by the patient at pan India and this facility is originated by The King George's. Additionally India is advancing the customary prescriptions and practices of ayurveda, yoga, naturopathy, unani, siddha and homeopathy. A telemedicine application has additionally been propelled that interfaces patients in remote facilities with the specialists in tertiary emergency clinics by means of a video conference, propelled through BlackBerry Messenger. The specialist at that point performs live eye to eye meeting for the patient by methods for a video session.

\section{Indian Internet Pharmacies Association (IIPA)/ Digital Health Platforms (DHP)}

In the first meeting of IIPA formerly called DHP laid some rule and regulation for the operation of online drug store in the leadership of Kiran Divakaran, secretary IIPA. The rules are as follows:-
1. No one can sale any medicines without prescribed by doctor.

2. No drug store sale the drugs listed out in Schedule X.

3. Registered Pharmacist will approve the packing of medicines.

4. Every drug store will issues invoice of sales.

The IIPA likewise is working effectively with the Central Government to acquire changes to the guidelines including the utilization of AADHAAR Number connected medicines to guarantee there is no misuse.

\section{Indian Online Pharmacy}

In India, there are several organizations which deals in online pharmacy such as Netmeds.com, Medlife.com, etc. The details are as follows:

\section{Netmeds.com - the trusted Online Medicine Partner}

Netmeds.com, India Ki Pharmacy is brought to you by the Dadha \& Company - one of India's most confided in pharmacies, with more than 100 years' involvement in apportioning quality prescriptions. At netmeds.com, we help you care for your own wellbeing easily just as deal with friends and family any place they may reside in India. You can purchase and send medcines from any side of the nation - with only a couple of snaps of the mouse.

At netmeds.com, we make a wide scope of doctor prescribed prescriptions and other health items advantageously accessible all over India. Indeed, even second and third level urban communities and provincial towns would now be able to approach the most recent prescriptions. Since we likewise offer conventional options in contrast to most medications, online purchasers can anticipate huge reserve funds. The main points regarding this company are as follow:

* Excellence, Expertise and Experience in Pharma since 1914.

* Happy and Hassle-free user experience for lakhs of customers in more than 850 cities \& towns.

* Pan India Delivery with coverage of over 19,000 PIN codes.

* 35,000+ products. Near $100 \%$ fulfillment rate. Most preferred online pharmacy.

\section{Convenience}

Overwhelming traffic, absence of stopping, rainstorm, shop shut, neglect... these are a portion of the reasons that could prompt skipping of essential prescriptions. Since taking medicines consistently is a basic segment of overseeing constant ailments, it's best not to come up short on basic prescriptions. Simply sign on to netmeds.com, submit your request on the web and have your medicines conveyed to you - without leaving the solace of your home.

Furthermore, with simple access to solid medication data, you become more acquainted with about your drug at netmeds.com, and once you're a Netmeds client, you'll get normal refill updates, so you'll

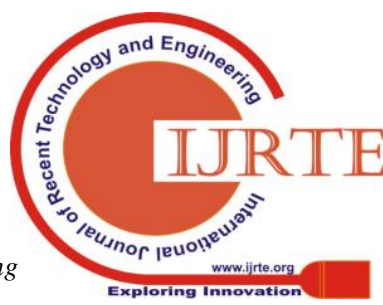


never again miss the mark concerning medicines.

\section{ONE-STOP SHOP}

At netmeds.com, we not just furnish you with a wide scope of drugs recorded under different classifications; we additionally offer a wide decision of OTC items including health items, nutrients, diet/wellness supplements, herbals items, torment relievers, diabetic consideration units, child/mother care items, beauty care items and surgical supplies.

\section{Trust}

Netmeds.com proceeds with a heritage of 100 years of achievement in the pharmaceutical business. We are committed to provide reliable, safe and affordable prescriptions just as a client support way of thinking that is deserving of our esteemed clients' loyalty. We offer a predominant web based shopping background, which incorporates simplicity of route and outright value-based security.

\section{Medlife.com}

Medlife.com is a creative healthcare organization which means to be pioneers in healthcare services that expedites all partners a solitary stage, which thusly will empower our regarded clients to encounter what smooth and consistent medicinal services administration truly feels like. We at Medlife have figured out how to cut a specialty for ourselves as one of the main medicinal services specialist organizations based on our technological and area ability. Our definitive objective is to guarantee that a human service is conveyed in a basic, reasonable and open way.

Medlife.com is an 'Innovation organization with a heart and dream that each Indian gets the chance to get to the most ideal medicinal services'. We expect to be a one stop medicinal services center point that would expedite all partners a solitary stage which would empower our clients with a consistent healthcare experience. In short we target making healthcare conveyance basic, open and reasonable. Right now, the organization is operational in 13 areas crosswise over India, Medlife.com will be operational PAN India quickly. We are sponsored by advertisers with humongous involvement in pharmaceutical and medicinal services online business organizations combined with owning fruitful worldwide internet business for 10 years in addition to. It's Engineering division is a shark tank with best personalities from crosswise over Domains, there are a lot more who carry with them many years of space aptitude, energy to manufacture the cutting edge innovation and with a drive to succeed and take on difficulties. This inclination for exceeding expectations in all that we do is what is helping Medlife with the edge and competency to become quicker.

A. Benefits

* Convenience of ordering from mobile
*asy to order and track
* Free home delivery for all orders
* Delivery within 24 to 48 hours
* Best-in-class experience

B. How does it work?

You upload the prescription image.

We collect the prescription from your address (mandatory).

We deliver medicines along with your prescription.

\section{RESEARCH MethodologY}

Research in like manner refers to a quest for learning. One can likewise characterize inquire about as a logical and efficient quest for relevant data on a particular theme. Truth be told, look into is a craft of scientific investigation. A research methodology is the method for characterizing the action of research, the system of research, deciding the components of such research regarding logically received models or methodologies, plans and tools.

In this research, researchers took the analytical and descriptive approach. The principle population of this study is western part of Uttar Pradesh and took 80 samples. The tool used in this study is questionnaire and the researchers used the random and convenient sampling.

Table 1 Research Methodology

\begin{tabular}{|c|c|c|}
\hline S. No. & Particulars & Data \\
\hline 1 & Data Type & Primary and Secondary Data \\
\hline 2 & Sampling Unit & Service Industry \\
\hline 3 & Sampling Type & Random and Convenience Sampling \\
\hline 4 & Sample Size & 80 \\
\hline 5 & Research Tool & Questionnaire \\
\hline 6 & Type of Research & Analytical and Descriptive Research \\
\hline 7 & Data Collection Method & Survey \\
\hline 8 & Survey Area & Western part of Uttar Pradesh \\
\hline
\end{tabular}

Formulation of Research Hypothesis

$>\mathbf{H}_{\mathbf{0}}$ : The level of Customer Satisfaction from online pharmacy system is significant.

Data Analysis through Statistical Techniques
In this research, researchers used the following statistical techniques:

$>$ Mean

$>$ Standard Deviation

$>\mathrm{Z}$ - Test 
Survey Findings and Testing of Hypotheses

This section of the research paper covers the testing of hypotheses of the data set. The findings of every question, which are asked by the respondents, are as follows:

Rate on the various challenges and benefits associated with the implementation of e-commerce in Supply Chain Management.
The accompanying depiction demonstrates the rating of different challenges and benefits related with the execution of e-commerce in Supply Chain Management among Indian Online Pharmacy:

Table 2 Challenges and Benefits of e-commerce in Supply Chain Management

\begin{tabular}{|c|c|c|c|c|c|c|c|c|}
\hline & & & \multicolumn{5}{|c|}{ Challenges and Benefits of e-commerce } & \multirow[b]{2}{*}{ Total } \\
\hline & & & $\begin{array}{l}\text { Awarenes } \\
\text { s about } \\
\text { online } \\
\text { pharmacy }\end{array}$ & $\begin{array}{c}\text { Awareness } \\
\text { about } \\
\text { attractive } \\
\text { feature of } \\
\text { Online } \\
\text { Pharmacy } \\
\text { like better } \\
\text { price, door } \\
\text { step } \\
\text { delivery, } \\
\text { drug } \\
\text { information } \\
\text {,etc. } \\
\end{array}$ & $\begin{array}{l}\text { There is a } \\
\text { chance of } \\
\text { delivering } \\
\text { wrong } \\
\text { medicines } \\
\text { and delay in } \\
\text { delivery }\end{array}$ & $\begin{array}{c}\text { Non- } \\
\text { availability } \\
\text { of } \\
\text { particular } \\
\text { brand of } \\
\text { medicine } \\
\text { especially } \\
\text { prescribed } \\
\text { by doctor }\end{array}$ & $\begin{array}{l}\text { Satisfaction } \\
\text { with the } \\
\text { current } \\
\text { community } \\
\text { pharmacy } \\
\text { services }\end{array}$ & \\
\hline \multirow[t]{10}{*}{ Answers } & \multirow{2}{*}{$\begin{array}{l}\text { Strongly } \\
\text { Agree }\end{array}$} & & 35 & 26 & 16 & 26 & 36 & 139 \\
\hline & & \% within & 43.75 & 32.50 & 20.00 & 32.50 & 45.00 & \\
\hline & \multirow[t]{2}{*}{ Agree } & Count & 26 & 34 & 20 & 18 & 26 & 124 \\
\hline & & $\%$ within & 32.50 & 42.50 & 25.00 & 22.50 & 32.50 & \\
\hline & \multirow[t]{2}{*}{ Neutral } & Count & 12 & 16 & 26 & 14 & 12 & 80 \\
\hline & & $\%$ within & 15.00 & 20.00 & 32.50 & 17.50 & 15.00 & \\
\hline & \multirow[t]{2}{*}{ Disagree } & Count & 5 & 4 & 12 & 20 & 2 & 43 \\
\hline & & $\%$ within & 6.25 & 5.00 & 15.00 & 25.00 & 2.50 & \\
\hline & \multirow[t]{2}{*}{$\begin{array}{l}\text { Strongly } \\
\text { Disagree }\end{array}$} & Count & 2 & 0 & 6 & 2 & 4 & 14 \\
\hline & & $\%$ within & 2.50 & 0 & 7.50 & 2.50 & 5.00 & \\
\hline \multirow{2}{*}{ Total } & & Count & 80 & 80 & 80 & 80 & 80 & 400 \\
\hline & & $\%$ within & 100 & 100 & 100 & 100 & 100 & 100 \\
\hline
\end{tabular}

The above table 2 tells about the different challenges associated with online pharmacy practices:

1. Are you aware about online pharmacy?

The findings of this statement have been portrayed in the accompanying points:

* Null Hypothesis:There is no awareness about online pharmacy.

* N: 80

* Means: 4.088

* Standard Deviation: 1.027

Df: 79

* Sig. (2-tailed): 0.028

* Null Hypothesis: Rejected

Interpretation: It has been seen from the table 2 that $76.2 \%$ respondents are concurring with the above articulation and this is additionally advocated by the estimation of mean (4.088) and standard deviation (1.027). For testing this hypothesis, the determined significance value of Z-test is
0.028 which is less than the p-value $(0.05)$. Thus, it is translated that the null hypothesis is rejected. In this manner, most of the people are well aware about the online pharmacy.

2. Are you aware about the attractive features of Online Pharmacy like better price, door step delivery, drug information, etc.?

The findings of this statement have been portrayed in the accompanying points:

* Null Hypothesis:There is no awareness about the attractive features of Online Pharmacy like better price, door step delivery, drug information, etc.

* N: 80

* Means: 4.028

* Standard Deviation: 0.851

* Df: 79

* Sig. (2-tailed): 0.041

* Null Hypothesis: Rejected 
Interpretation: It has been seen from the table 2 that $75 \%$ respondents are concurring with the statement. The estimation of mean is 4.028 and standard deviation is 0.851 . For testing this hypothesis, the determined significance value of Z-test is 0.041 which is smaller than the p-value (0.05). Along these lines, it is deciphered that the null hypothesis is rejected. In this manner, most of the people are well aware about the attractive features of Online Pharmacy like better price, door step delivery, drug information, etc.

3.There is a chance of delivering wrong medicines and delay in delivery.

The findings of this statement have been portrayed in the accompanying points:

* Null Hypothesis:There is no chance of delivering wrong medicines and delay in delivery.

* N: 80

* Means: 3.35

* Standard Deviation: 1.174

* Df: 79

* Sig. (2-tailed): 0.000

* Null Hypothesis: Rejected

Interpretation:It is obvious from the table 2 that $45 \%$ respondents are agreeing and $32.5 \%$ respondents are discovered neutral. The estimation of mean is 3.35 and standard deviation is 1.174 . To test the hypothesis, Z-test has been done and the processed significance value $(0.000)$ is smaller than the p-value (0.05). Along these lines, it is deciphered that the null hypothesis is rejected. In this manner, there is a chance of delivering wrong medicines and delay in delivery.

4.Non- availability of particular brand of medicine especially prescribed by doctor.

The findings of this statement have been portrayed in the accompanying points:

* Null Hypothesis:There is no chance of non-availability of particular brand of medicine especially prescribed by doctor.

* N: 80

* Means: 3.575

* Standard Deviation: 1.243

* Df: 79

* Sig. (2-tailed): 0.074

*ull Hypothesis: Accepted

Interpretation: The estimation of mean and standard deviation are 3.575 and 1.243 individually. Z-test has been directed to test this hypothesis and it is discovered that the figured significance value $(0.074)$ is more than the p-value (0.05). Along these lines, it is translated that the null hypothesis is accepted. In this manner, there is no chance of non-availability of particular brand of medicine especially prescribed by doctor.

\section{Satisfaction with the current community pharmacy services.}

The findings of this statement have been portrayed in the accompanying points:
* Null Hypothesis:The satisfaction level with the current community pharmacy services is not significant.

* N: 80

* Means: 4.1

* Standard Deviation: 1.068

* Df: 79

* Sig. (2-tailed): 0.027

* Null Hypothesis: Rejected

Interpretation: It has been seen from the table that $77.5 \%$ respondents are agreeing with the above statement and this is additionally supported by the estimation of mean (4.1) and standard deviation (1.068). For testing this hypothesis, the determined significance value of Z-test is 0.027 which is smaller than the p-value (0.05). Thus, it is deciphered that the null hypothesis is rejected. Consequently, most of the respondents are satisfied with the current community pharmacy services.

\section{OUTCOME OF THE STUdY}

The outcome of the study is explain in the following points:

* This study explain several features of supply chain management and information technology infrastructure which are related to online pharmacy system of India.

* This research also emphasizes on risks and concerns of online pharmacy.

* This article depicts about the online pharmacies laws in India and its' recent developments.

* This study also describe relevant information regarding Indian online pharmacy companies.

* This study explain the benefits and procedure of online purchasing medicines.

\section{Suggestions}

In the light of foregoing analysis, findings and observations, some broad suggestions have been recommended. The present research has indicated some of the facts about online pharmacy services. So based on these observations, some specific suggestions are as follows:

* The filling of questionnaire form is simple to some extent.

* The file size of the prescription will increase.

* The information related to the salt of the medicine should be more specific.

* There is an option related to medical advice/ online doctor is available.

* The rules and regulations related to online pharmacy system must be available on the website.

Contributions of Online Pharmacy System to our Society The contributions of Online Pharmacy System to our society are as follows:

* The awareness of medicine information will increase.

* Customers are getting discounted price.

* In case of patient, who is not able to reach the medical store for purchasing the necessary medicines, door step delivery is significantly appreciable. 
* It is helpful in personalize medicine reminder services.

* This system is quite beneficial in case of access to the drug information.

\section{Limitations of Research}

The limitations of research are as follows:

The research area of the study is the entire western part of Uttar Pradesh but it is very difficult to cover each and every district of the specified region.

$>$ The research topic is very wide and the researcher has limitation of time to cover each and every aspect related to online pharmacy system. Thus time factor can be considered as one of the limitations.

$>$ This research is completely based on the information provided by the respondents. Therefore, the accuracy of findings and results of this research are not fool proof.

$>$ The results of this study may change due to demographic characteristics and time of the study.

$>$ The present research has focused only on the opinions of those respondents, which are involved in online pharmacy.

The above points explain the limitations of the research.

\section{CONCLUSION}

This research paper shows the role of e-commerce in Supply Chain Management among Indian online pharmacies companies. This study depicts the various features of Supply Chain Management and also describes the required IT infrastructure for Supply Chain Management System. The Indian online pharmacy system is growing day by day. Several organizations like Netmeds.com, Medlife.com, etc. are playing important role in distribution of medicine among the customers. This article covers various tactics like online pharmacy laws in India, recent developments, Indian online pharmacy, etc. This research describe that most of the people are well aware about the online pharmacy in India. In India, people are also aware about the attractive features of Online Pharmacy like better price, door step delivery, drug information, etc. Atlast, most of the respondents are satisfied with the current community pharmacy services.

\section{REFERENCES}

1. Agarwal, D. K. (2000). Integrated IT Solutions for L \& SCM: A Case Study of Telco. Proceeding of ICQRIT, GGS Indraprastha University, New Delhi.

2. Alamelu R. et.al.(2016). Online Pharma Retail is a promising/ umpromising Avenue: An Indian Context. Asian Journal of Pharmaceutical and Clinical Research,9 (2), pp. 26-29.

3. Christopher, M. (1992). Logistics and Supply Chain Management. Financial Times, London, Pitman Publishing.

4. Hertig J. et.al. (2017). Evaluation of Risk Perception associated with Online Pharmacy Use. ASOP Global Foundation, pp. 1-9.

5. Kothari, C.R., and Garg, G. (2014). Research Methodology: Methods and Techniques, New Age International Publishers, New Delhi.

6. Nikakhtar, N. and Jianzheng, Y. (2012). Role of e-commerce in Supply Chain Management to minimize costs. African Journal of Business Management, 6 (17), pp. 5671 - 5683.

7. Obrein, M. (2001). Introduction to Information Systems. McGraw-Hill, New York.

8. Sah R. K. et.al. (2018). Awareness and Behavioral outlook towards online pharmacy services among consumers in Delhi, India: A Pilot
Survey.European Journal of Pharmaceutical and Medical Research, 5 (3), pp. 552 - 557.

9. Snyder and Rell (2013). E-Commerce and Supply Chain Management Proceedings of ASBBS, 20 (1), pp. 237- 242.

10. Uttarwar, V.R. and Riat, R. S. (2018). Key Emerging Trends in Supply Chan management: Indian Industry Context. International Journal of Basic and Applied Research, 8 (6), pp. 271-280.

11. Xiao, S. and Zhang, S. (2017). The Role of Supply Chain Management in E-Commerce. Retrieved from http://unpan1.un.org/intradoc/groups/public/documents/un/unpan001216. pdf on June 15, 2018.

12. Yang, M. (2012). Supply Chain Management under E-Commerce Environment. International Journal of Innovation, Management and Technology, 3 (3), pp. 210 - 212.

13. Ying Yu, Xin Wang, Ray Y. Zhong, G.Q. Huang, (2017). E-commerce logistics in supply chain management: Implementations and future perspective in furniture industry. Industrial Management \& Data Systems, 117 (10), pp.2263-2286. 